\title{
Fuzzy Logic Based Alert on Cochliobolus Miyabeanus to Control the Rice Crop Loss
}

\author{
Dekka Satish, K.NarasimhaRaju, Bonu Satish, Koduru Suresh, Dasari Manendra Sai
}

\begin{abstract}
Agriculture is a source of living in many areas and acts a backbone for the Indian economy. Agriculture crops are affected by fungus and bacteria to cause diseases in the plant. Brown spot is a serious hazard that takes place on leaves of the rice plant. The presence of fungus 'Cochliobolus miyabeanus' is the main factor for brown spot disease. The severity of the disease depends on growth of the fungus. The development of fungus depends on several factors such as temperature, humidity and rainfall. Whenever the disease occurs on a plant, level of the infection plays an importance in crop yield. Most of the farmer follow books or use their experience to detect the disease in rice plants which is a time-consuming process and requires lot of attention to produce more rice yield is a challenging task. Fuzzy logic is identified as powerful tool for disease detection. In this paper, fuzzy logic system is proposed to determine the level of presence of Cochliobolus miyabeanus and alert the farmer to take the primitive steps.
\end{abstract}

Keywords : Fuzzy Logic, Disease Determination, IoT, Rice Crop,

\section{INTRODUCTION}

Majority of the human beings in India depends on farming and become a livelihood. Agriculture has a major impact on Indian economy. Therefore there is a necessity to increase the production of the crops. Unfortunately, Agriculture is suffering from several problems such as floods, droughts and disease of the plants. The detection of the disease occurring in plants and level of the disease can be predicted. Early detection and preventive steps can control the loss of crop yield.

Rice is a highly demand food for many areas in India. These types of plants are affected mainly by fungus and bacteria. Leaf blast and Brown spot are the common diseases that occur frequently in rice crops. Brown spot is a serious infection that is present on leaves of the rice plant.

Revised Manuscript Received on February 05, 2020

* Correspondence Author

Dekka Satish *,CSE Department, LENDI,Viziangaram, AP, INDIA.

Email:satishmtech4u@gmail.com

Dr.K.NarasimhaRaju ,CSE Department, LENDI ,Viziangaram, AP,

INDIA.Email:bcoolmind@gmail.com

Koduru Suresh, SAP Labs Bangalore, India

Email: koduru112@gmail.com,

Bonu Satish , CSE Department, LENDI, Viziangaram, AP, INDIA.

Email: vsp.satish@gmail.com,

Dasari Manendra Sai ,CSE Department, Sai Ganapathi Engineering College,AP, INDIA.Email: sgec.csehod@gmail.com

(c) The Authors. Published by Blue Eyes Intelligence Engineering and Sciences Publication (BEIESP). This is an open access article under the CC BY-NC-ND license (http://creativecommons.org/licenses/by-nc-nd/4.0/)
The presence of fungus 'Cochliobolus miyabeanus' is the main factor for brown spot disease. The growth of the fungus depends on temperature, humidity and rainfall.

Most of the farmer follow books or use their experience to detect the disease in rice plants. Some farmers get information and take decisions depending on experts but unfortunately their availability at all times is uncertain. Therefore, paying attention all the times or presenting all the time in farming field is a difficult task for the farmers. To solve these types problems, Fuzzy logic is identified as powerful tool for disease detection in agriculture. The centric idea of this work is to identify the severity of the rice disease and alert the farmer to control the loss of crop at early stages.

\section{RELATED WORK}

Day by Day, Every country faces new challenges in the Environment, Agriculture and Population. Several plants in agriculture are affected with new diseases resulting in yield loss. In this view, new technologies have to be incorporated better productivity in agriculture. The disease occurring in plants can be determined by analyzing the images obtained. Phadikar et al. [2] proposed disease detection techniques on rice crops through images.But all these techniques detect the disease based on the images.

Currently artificial Intelligence techniques are becoming a part of the activity in agriculture field. Especially artificial fuzzy logic techniques [5] [6] have a greater attention in various sectors across the world. Due to human thinking behavior of fuzzy logic, it is implemented in agriculture sector for various applications. Esther Rodriguez et.al [7] designed an index technique depending on multi-valued logic to assess the quality of soil. Pushkar Goel et.al [8] applied fuzzy logic for crop quality assessment. S.M.Mazloumzadeh Et.al [9] utilized mamdani variant architecture of the multi-valued logic to classify productive trees depending on yield and other factors to generate TTQM for each grove. Their work indicates that it helps in reducing the costs involved during the process. N.Alavi et.al [10] applied mamdani architecture of fuzzy inference system to classify mozafati dates and concluded that fuzzy systems provide better results. Ximing Sun et.al [11] applied fuzzy logic theory to determine the consumption values of consumers in china. P.J.Kiaet.al [12] designed a mamdani fuzzy controller to estimate the quantity of water uptake of plants. E. Neamatollahi et.al [13] designed fuzzy system to align the crops in good pattern to achieve better results.

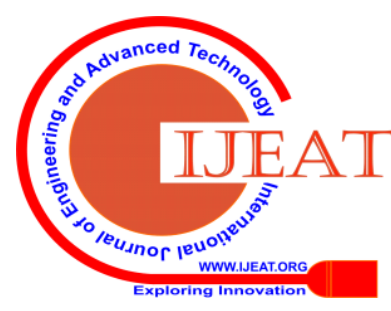


Fuzzy Logic Based Alert on Cochliobolus Miyabeanus to Control the Rice Crop Loss

Zohaib Mushtaq et.al [15] designed a fuzzy logic system to automate the irrigation using the software MATLAB. Muhammad Imran et.al [16] designed a multi-valued logic system to control the flow of dam gates. They designed in MATLAB considering mamdani architecture. Water level and water speed considered as inputs while flow control as output.

P. Roseline et.al [17] studied the effective use of fuzzy methods in agricultural field. L.Lamastra et.al [18] designed a model using fuzzy logic for obtaining a general judgment in vineyard management. N.Tremblay et.al [19] developed a fuzzy inference system to obtain some recommendations regarding the fertilizer. They concluded that fuzzy inference system acts an aid to include expert knowledge in generating recommendations.

\section{METHODOLOGY}

Recently fuzzy logic attracted many researchers to incorporate it in various fields. Cochliobolus miyabeanus is a fungus that causes brown spot disease in rice ultimately leads to loss of crop yield.Therefore a mechanism is necessary to identify the level of disease and alert the same to farmer. A fuzzy logic system is proposed to determine the level of presence of Cochliobolus miyabeanus and alert the farmer to take the primitive steps.

Brown spot disease in rice is mainly caused by Cochliobolus miyabeanus which depends on the factors temperature and relative humidity levels mainly. The color of the leaf acts an indicator of the development of fungus. Therefore a fuzzy logic design is developed using MATLAB [22] taking temperature and relative humidity level as input and the degree of the presence of fungus with brown spot disease level as an output and is presented in figure 2. The Mamdani architecture is used during the development of the design. The membership functions for the input variables are trapezoidal and for the output it is Triangular as shown in the figures 3,4 and 5 .

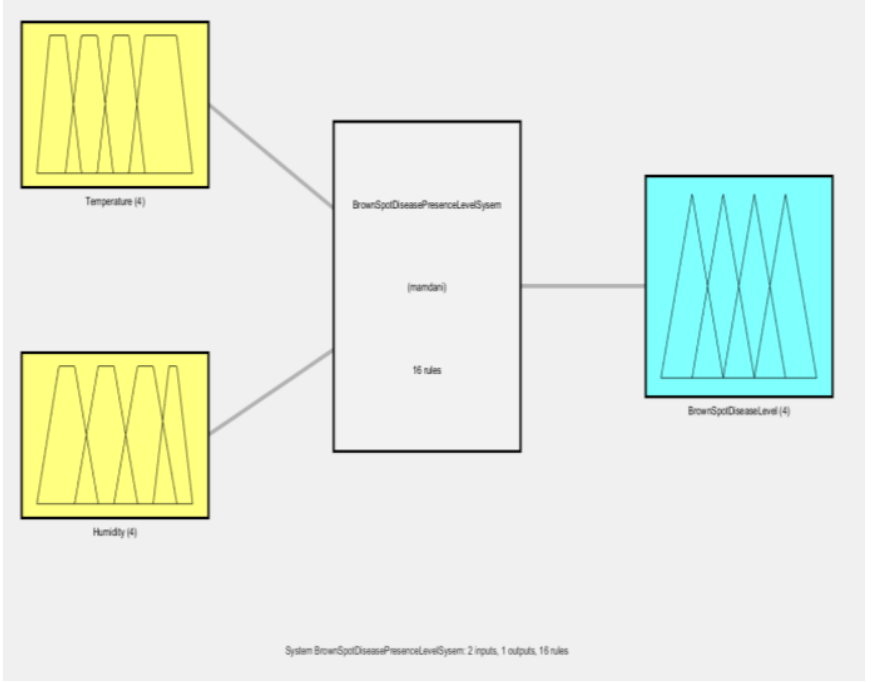

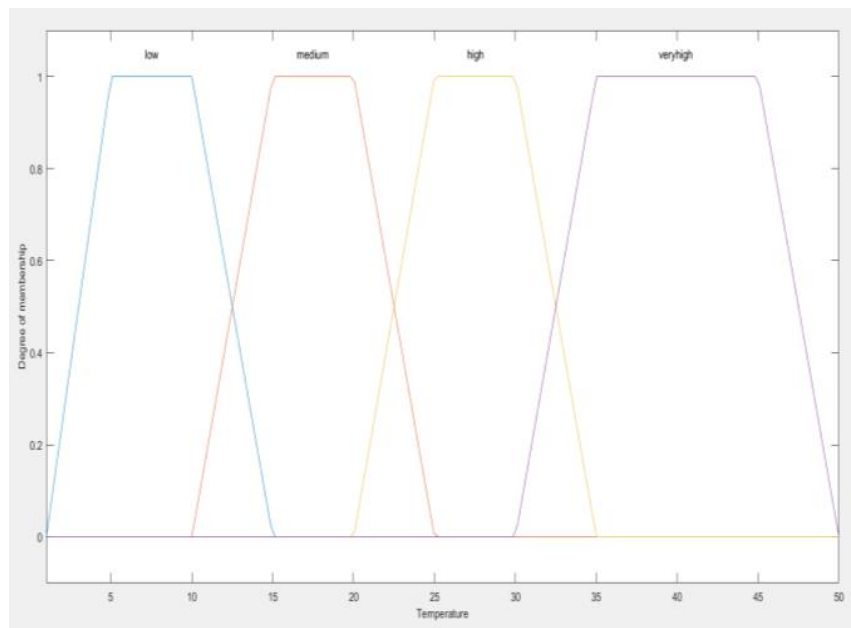

Figure 3: Membership function for the input 'Temperature'

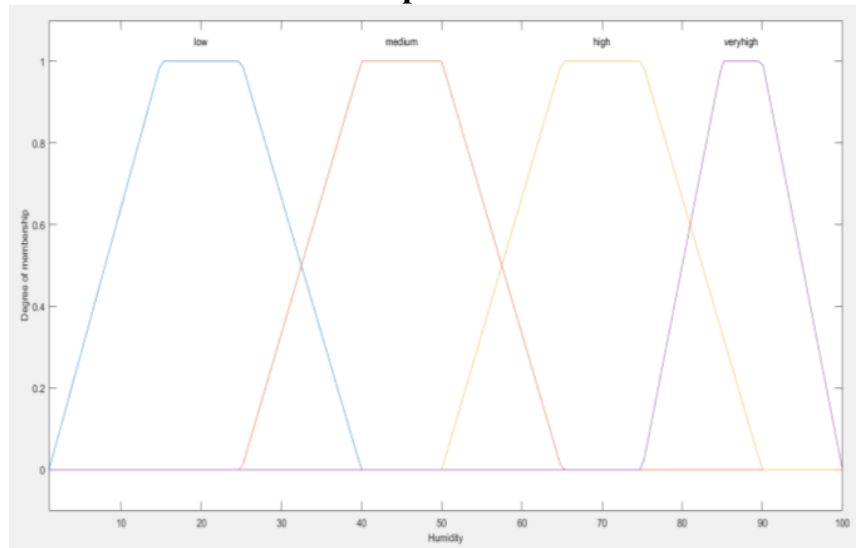

Figure 4: Membership function for the input 'Humidity'

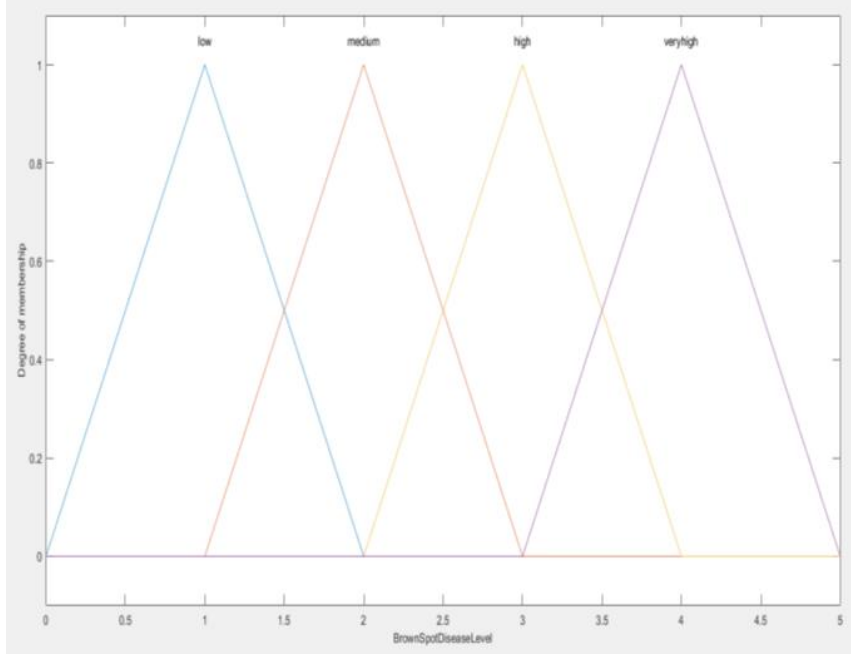

Figure5: Membership function for the Output 'BrownSpotDiseaseLevel' 


\section{FUZZY RULE BASE}
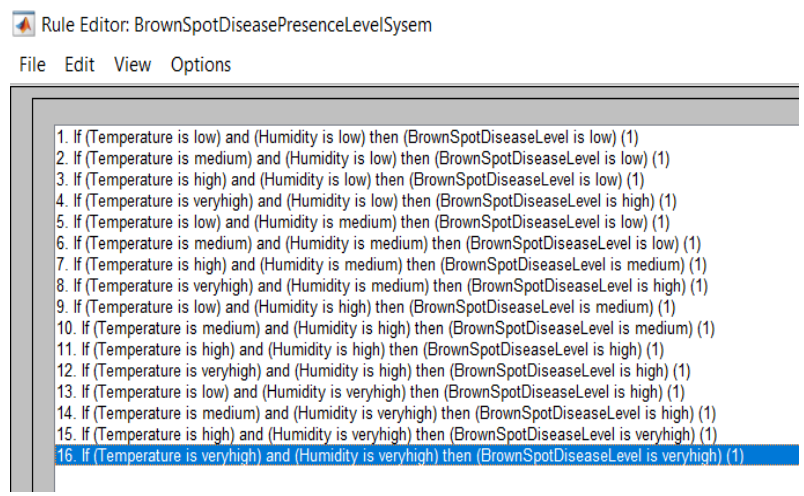

Results

The following diagram predicts the severity of the disease based on the temperature and humidity. The table 1 presents the comparative analysis with the existing technologies.

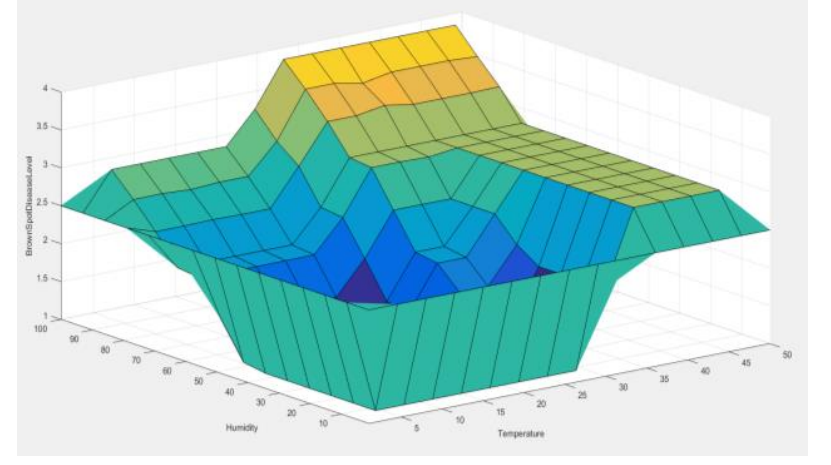

Figure 6: Surface view of the Brown Spot Disease Level system

Table 1: Comparative analysis of proposed technique with the exiting methods

\begin{tabular}{|l|l|l|l|}
\hline $\begin{array}{l}\text { Technology } \\
\text { /Method }\end{array}$ & $\begin{array}{l}\text { Time } \\
\text { consuming }\end{array}$ & $\begin{array}{l}\text { Execution } \\
\text { Step }\end{array}$ & Cost \\
\hline Manual & Very high & $\begin{array}{l}\text { Continuous- } \\
\text { monitoring }\end{array}$ & Moderate \\
\hline $\begin{array}{l}\text { Image } \\
\text { processing }\end{array}$ & Moderate & $\begin{array}{l}\text { Post } \\
\text { Continuous }\end{array}$ & Moderate \\
\hline Fuzzy Logic & Very less & $\begin{array}{l}\text { Preventive } \\
\text { step }\end{array}$ & Very less \\
\hline
\end{tabular}

\section{CONCLUSION}

A huge loss can be expected, if the disease on plants cannot be predicted at an early stage. The proposed work presented a Fuzzy logic system to address the problem of rice disease and alert the farmer to take the necessary steps. This work acts as an aid to control rice disease and increase the production of the rice crop through early notification.

\section{REFERENCES}

1. S. Phadikar, J. Sil, and A. K. Das, "Classification of Rice Leaf Diseases Based onMorphological Changes," International Journal of Information and Electronics Engineering, vol. 2, p. 460, 2012.

2. Klir, G.J., Yuan, B., 1995. Fuzzy sets and fuzzy logic: theory and applications, 1st ed.Prentice Hall, Upper Saddle River, NJ.
3. Roberto Peche and Esther Rodríguez, "Environmental impact assessment procedure: a new approach based on fuzzy logic", Environmental Impact Assessment Review , Elsevier, Volume 29,Issue 5, pages 275-283, September 2009.

4. Esther Rodriguez, Roberto Peche, Carlos Garbisu, Inaki Gorostiza, Lur Epelde, Unai Artetxe, Amaia Irizar, Manuel Soto, Jose M Becerril and Javier Etxebarria, "Dynamic soils based on fuzzy logic", Ecological Indicators, Quality Index for agricultural Elsevier, Volume 60, pages 678-692, January 2016.

5. Pushkar Goel, Samiksha Goel and Shiven Bhatia, "Food quality assessment using fuzzy logic", $2^{\text {nd }}$ International Conference on Computing for sustainable Global Development, pages 1459 - 1462 , IEEE, March 2015.

6. Mazloumzadeh, S.M. Shamsi, M. and Nezamabadi-pour, H. (2009) Fuzzy logic to classify date palm trees based on some physical properties related to precision agriculture, precision Agriculture.

7. N. Alavi, "Quality determination of Mozafati dates using mamdani fuzzy inference system", Journal of the Saudi society of Agircultural Sciences, Volume 12 , Issue 2, pages 137-142, June 2013.

8. Ximing Sun and Ray Collins, "The application of fuzzy logic in measuring consumption values:Using data of Chinese consumers buying imported fruit", Elsevier, Food Quality and Preference Volume 18, Issue 13, pages 576-584, April 2007.

9. P. J. Kia and A. T. Far and M. Omid and R. Alimardani and L. Naderloo, Intelligent control based fuzzy logic for automation of greenhouse irrigation system and evaluation in relation to conventional systems, World Applied Sciences Journal, 6(1), 16-23, 2009.

10. E.Neamatollahi, J.Vafabakshi, M.R.Jahansuz and F.Sharifzadeh, "Agicultural Optimal Cropping Pattern Determination based on Fuzzy System", Fuzzy Information and Engineering, Elsevier, Volume 9, 479-491, 2017.

11. Zohaib Mushtaq, Syeda Shaima Sani, Khizar Hamed, Amjad Ali, Aitizaz Ali, Syed Muhammad Belal and Abid A. Naqvi, "Automatic Agricultural land irrigation system by fuzzy logic", International conference on information science and control engineering, pages 871-875, IEEE, July 2016.

12. P. Roseline, N.Ganesan , J.Clarence and J.M.Tauro, "A study of applications fuzzy logic in domains of agricultural sciences", International Conference of Current Trends in Advanced Computing ICCTAC 2015(1), pp 15-18, May 2015

13. L.Lamastra, M. Balderacchi, A.Di Guardo, M.Mochiero and M.Tervisan, "A novel fuzzy expert system to assess the sustainability of the viticulture at the wine-estate scale", Elsevier, Science of the Total Environment, Volume 572, pages 724-733, December 2016.

14. Tremblay, N., Bouroubi, M.Y., Panneton, B., Guillaume, S., Vigneault, P., Be'lec, C., "Development and validation of fuzzy logic inference to determine optimum rates of $\mathrm{N}$ for corn on the basis of field and crop features", Precision Agriculture, Volume 11, Issue 6, pages 621-635, December 2010.

15. T. J. Ross, Fuzzy Logic with Engineering Applications. New York: McGraw-Hill, Inc., 1995.

16. MATLAB https://in.mathworks.com/products/matlab.html

\section{AUTHORS PROFILE}

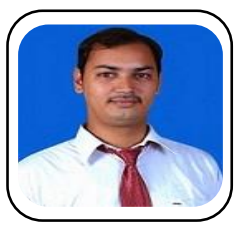

Satish Dekka, M.Tech., (Ph.D.),Associate Professor, CSE Department, Lendi ,Vizianagaram. Expertise and interest Include:Computer Networks, Wireless Sensor networks \& internet of things(IoT).

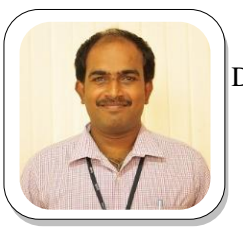

Dr.K.NarasimhaRaju,Professor,

CSE Departmen

LENDI, Viziangaram, Expertise and interest include: Computer Networks, Mobile Ad-hoc Networks \& Soft Computing.

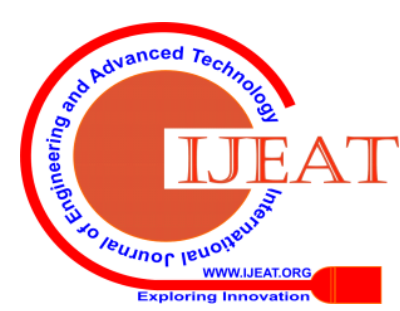


Fuzzy Logic Based Alert on Cochliobolus Miyabeanus to Control the Rice Crop Loss

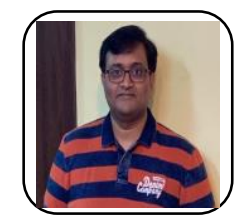

Koduru Suresh, M.Tech.,(Ph.D.), SAP Labs Bangalore, India. Expertise and interest include: Computer Networks, internet of things (IoT) \& Software Development.

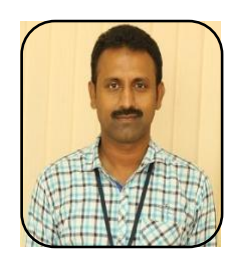

Bonu Satish, M.Tech.,(Ph.D.),Associate Professor, CSE Department, Lendi ,Vizianagaram.Expertise and interestInclude:ComputerNetworksSecurity,MANET

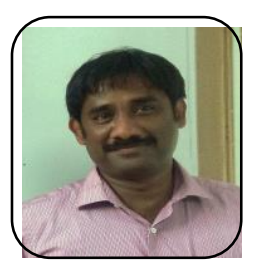

Dasari Manendra Sai *, M.Tech.,(Ph.D.), Associate Professor, CSE Department, SGEC,Expertise and interest include: Computer Networks, Cyber Security. 